\title{
The influence of thoracic duct ligation on long-term survival of patients with esophageal cancer: a propensity score-matched analysis
}

\author{
Xiang Fei", Xinyu Wang", Qijue Lu\#, Chaojing Lu, Hezhong Chen, Chunguang Li \\ Department of Thoracic Surgery, Changhai Hospital affiliated to Second Military Medical University, Shanghai, China \\ Contributions: (I) Conception and design: H Chen, C Li; (II) Administrative support: None; (III) Provision of study materials or patients: None; (IV) \\ Collection and assembly of data: X Fei; (V) Data analysis and interpretation: X Fei, Q Lu, X Wang, C Lu; (VI) Manuscript writing: All authors; (VII) \\ Final approval of manuscript: All authors. \\ \#These authors contributed equally to this work and are co-first authors. \\ Correspondence to: Hezhong Chen; Chunguang Li. Department of Thoracic Surgery, Changhai Hospital, Second Military Medical University, \\ Shanghai, China. Email: chzchanghai@163.com; smmuchanghai@163.com.
}

\begin{abstract}
Background: Ligation of the thoracic duct (LTD) is known to be a useful way to prevent postoperative chylothorax, but its impact on long-term survival is rare to be assessed.

Methods: Data from 609 patients with esophageal cancer who underwent esophagectomy from September, 2012, to January, 2014, were retrospectively collected. The study cohort was classified into two groups: the thoracic duct ligation group (LG) and the non-ligation group (NLG). Propensity score matching (PSM) was performed to control confounding factors between the two groups. Postoperative complications and length of stay were compared between the two groups. Overall survival was estimated using the Kaplan-Meier method, and compared using the log-rank test. Independent prognostic factors were determined using Cox regression analysis.

Results: After PSM, there were 185 patients in each of the two groups. LTD had no significant impact on chylothorax, anastomotic leak, recurrent nerve palsy, pneumonia and length of stay $(\mathrm{P}>0.05)$. The 1-, 3- and 5 -year survival rates were $87.0 \%, 64.1 \%$, and $50.9 \%$ in the LG, respectively, compared to $85.4 \%, 59.9 \%$, and $42.3 \%$, respectively, in the NLG. The differences between the 2 groups were not statistically significant $(\mathrm{P}=0.156)$. In the multivariable analysis, LTD was not an independent prognostic factor, neither before nor after PSM.

Conclusions: Our study demonstrated that LTD had no significant impact on postoperative complications or long-term survival in patients with esophageal cancer.
\end{abstract}

Keywords: Esophageal cancer; esophagectomy; thoracic duct ligation; prognosis

Submitted Mar 16, 2020. Accepted for publication Sep 02, 2020.

doi: $10.21037 /$ jtd-20-1341

View this article at: http://dx.doi.org/10.21037/jtd-20-1341

\section{Introduction}

The thoracic duct (TD) is part of the lymphatic system and functions to carry chyle. Chyle is a fluid which contains emulsified fats, proteins, sugars, lymphocytes, immunoglobulins, and various enzymes (1). The TD therefore plays a fundamental role in maintaining homeostasis. It is also prone to sustaining damage during thoracic operations for malignancies such as esophagectomy and lobectomy $(2,3)$. Postoperative chylothorax is a rare but serious complication that can occur after esophagectomy, with a reported incidence of up to $10 \%$ (4). If left untreated, chylothorax can lead to malnutrition, infection, circulatory failure, and even death (5). Since Lampson reported the first successful case in 1948 (6), ligation of the thoracic duct 
(LTD) has been used to prevent postoperative chylothorax after esophagectomy.

Previous studies have focused on the reduction of chylothorax as the only clinical goal in LTD, thus overlooking its impact on overall long-term survival (7). In a retrospective study, Hou et al. showed that prophylactic LTD had an unfavorable impact on the overall survival (OS) of patients with esophageal cancer (8). However, there were many confounders in the treatment groups, which may have introduced selection bias and reduced the credibility of the results. Therefore, the impact of LTD on long-term survival warrants further investigation.

To this end, we conducted a retrospective analysis using propensity score matching (PSM) to control for confounding factors between the two groups, and assessed whether LTD could affect long-term survival rates. We present the following article in accordance with the STROBE reporting checklist (available at http://dx.doi. org/10.21037/jtd-20-1341).

\section{Methods}

\section{Study population}

A retrospective analysis of 634 consecutive patients with esophageal carcinoma who underwent an esophagectomy between September, 2012, and January, 2014, at Changhai Hospital was conducted. The study was conducted in accordance with the Declaration of Helsinki (as revised in 2013). This study was approved by the Ethics Committee of Changhai Hospital (CHEC-2019-359) and informed consent was taken from all the patients. All patients included in the analysis fit the following criteria: (I) pathologically confirmed esophageal carcinoma or esophagogastric junction carcinoma; (II) tumors were completely resected during esophagectomy (R0 resection); and (III) patients had complete medical records. The exclusion criteria were as follows: (I) a history of previous or concurrent malignancies; or (II) incomplete resection of tumors.

Of the 634 esophageal carcinoma patients who underwent esophagectomy at Changhai Hospital, 609 were included in the analysis. Of the 25 patients excluded from the analysis, 18 had concurrent or previous malignancies and 7 had undergone incomplete resection. All of the patients included in the study were re-staged according to the $8^{\text {th }}$ edition of the American Joint Committee on Cancer (AJCC) classification system. Patients were classified into two groups based on their medical records: the thoracic duct ligation group (LG, n=241) and the non-ligation group (NLG, n=368).

\section{Surgical procedures and postoperative management}

Radical esophagectomy and regional lymph node dissections were performed in all patients. For the LG, the thoracic duct was ligated $2 \mathrm{~cm}$ above the diaphragm, approximately at the level of the ninth thoracic vertebra. The thoracic duct was ligated when intraoperative chylous leakage occurred, or injury to the thoracic duct was highly suspected.

Postoperative complications were defined as the occurrence of any surgery-related complications taking place in hospital after surgery, including chylothorax, anastomotic leak, recurrent nerve palsy, and pneumonia. Postoperative chylothorax was defined as triglyceride levels $>110 \mathrm{~mL} /$ day or by the presence of chylomicrons found in pleural fluid. Conservative treatment or LTD was applied to treat chylothorax according to each patient's condition. Other complications were diagnosed using the relevant diagnostic criteria.

\section{Follow-up}

Follow-up data were collected by contacting patients and their relatives by telephone or by obtaining their medical records. Routine examinations, such as physical examinations, blood chemistry analysis, and computed tomography (CT) scans of the thorax and abdomen were generally performed every 3 months for the first 2 years and every 6 months after that for 5 years. After 5 years, the patients were assessed annually. The end of the follow-up period was January, 2019. The median follow-up time was 46 months (range, 1-81 months) for all patients, and the rate of patients lost to follow-up was $13.3 \%$. Patients lost to follow-up were treated as censored data. All-cause mortality was the primary endpoint of this study.

\section{Statistical analysis}

Statistical analyses were performed using SPSS 24.0 (IBM, Chicago, IL, USA). Continuous variables were reported as mean \pm standard deviation (SD) and compared between the groups using $t$-tests. Categorical variables were reported as proportions and analyzed using a chi-square test. To minimize the differences between the two groups (LG vs. NLG), 1:1 propensity score matching (PSM) was performed, with a caliper width of 0.1 . Propensity scores 
Table 1 Data of 609 patients before propensity score-matching

\begin{tabular}{|c|c|c|c|}
\hline \multirow{2}{*}{ Characteristics } & \multicolumn{3}{|c|}{ Before matching } \\
\hline & NLG $(n=368)$ & $L G(n=241)$ & $P$ value \\
\hline Age (years) & $62.36 \pm 8.246$ & $60.98 \pm 7.362$ & 0.036 \\
\hline BMI $\left(\mathrm{kg} / \mathrm{m}^{2}\right)$ & $23.15 \pm 3.06$ & $23.04 \pm 2.76$ & 0.646 \\
\hline Gender & & & 0.589 \\
\hline Male & $288(78.30)$ & $193(80.10)$ & \\
\hline Female & $80(21.70)$ & 48 (19.90) & \\
\hline Hypertension & $91(24.70)$ & $56(23.20)$ & 0.674 \\
\hline Diabetes & $25(6.80)$ & $9(3.70)$ & 0.108 \\
\hline Smoking history & $204(55.40)$ & $145(60.20)$ & 0.248 \\
\hline Drinking history & $133(36.10)$ & $102(42.30)$ & 0.125 \\
\hline Tumor location & & & $<0.001$ \\
\hline Upper third thoracic & $11(3.00)$ & $17(7.10)$ & \\
\hline Middle third thoracic & $125(34.00)$ & $162(67.20)$ & \\
\hline Lower third thoracic & $121(32.90)$ & $60(24.90)$ & \\
\hline EGJ & $111(30.10)$ & $2(0.80)$ & \\
\hline Surgical approaches & & & $<0.001$ \\
\hline Sweet & $260(70.70)$ & $132(54.80)$ & \\
\hline Ivor-Lewis & 38 (10.30) & $47(19.50)$ & \\
\hline McKeown & $70(19.00)$ & $62(25.70)$ & \\
\hline Pathological T classification & & & 0.082 \\
\hline Tis & $8(2.20)$ & $5(2.10)$ & \\
\hline $\mathrm{T} 1$ & $71(19.30)$ & $56(23.20)$ & \\
\hline T2 & $82(22.30)$ & $62(25.70)$ & \\
\hline T3 & 199 (54.10) & $106(44.00)$ & \\
\hline $\mathrm{T} 4$ & $8(2.20)$ & $12(5.00)$ & \\
\hline
\end{tabular}

Table 1 (continued)

were based on age, gender, BMI, hypertension, diabetes, smoking, drinking, tumor location, surgical approach, pathologic $\mathrm{T}$ stage (pT stage), pathologic $\mathrm{N}$ stage ( $\mathrm{pN}$ stage), pathological type, tumor cell differentiation, minimally invasive surgery (MIS), neoadjuvant therapy, and endoscopic submucosal dissection (ESD). Survival rates were estimated using the Kaplan-Meier method and the differences between the two groups were analyzed using the log-rank test. Independent risk factors were determined using univariate and multivariate cox regression analyses. A
Table 1 (continued)

\begin{tabular}{|c|c|c|c|}
\hline \multirow{2}{*}{ Characteristics } & \multicolumn{3}{|c|}{ Before matching } \\
\hline & NLG (n=368) & LG $(n=241)$ & $P$ value \\
\hline Pathological N classification & & & $<0.001$ \\
\hline NO & $169(45.90)$ & $142(58.90)$ & \\
\hline N1 & $111(30.20)$ & $72(29.90)$ & \\
\hline N2 & $58(15.80)$ & $23(9.50)$ & \\
\hline N3 & $30(8.20)$ & $4(1.70)$ & \\
\hline Pathological types & & & $<0.001$ \\
\hline Adenocarcinoma (AD) & $106(28.80)$ & $5(2.10)$ & \\
\hline Squamous cell (SC) & $231(62.80)$ & $213(88.40)$ & \\
\hline Others & $31(8.40)$ & $23(9.50)$ & \\
\hline Differentiation & & & 0.014 \\
\hline G1 & $23(6.30)$ & $31(12.90)$ & \\
\hline G2 & $247(67.10)$ & $160(66.40)$ & \\
\hline G3 & $63(17.10)$ & $27(11.20)$ & \\
\hline NA & $35(9.50)$ & $23(9.50)$ & \\
\hline MIS & $60(16.30)$ & 45 (18.70) & 0.449 \\
\hline Neoadjuvant & $2(0.50 \%)$ & $7(2.90 \%)$ & 0.044 \\
\hline ESD & $6(1.60 \%)$ & $6(2.50 \%)$ & 0.654 \\
\hline Chylothorax & $3(0.81 \%)$ & $2(0.83 \%)$ & 1.000 \\
\hline Anastomotic leak & $22(6.00 \%)$ & $23(9.50 \%)$ & 0.100 \\
\hline Recurrent nerve palsy & $2(0.50 \%)$ & $6(2.50 \%)$ & 0.089 \\
\hline Arrhythmia & 55 (14.90\%) & 27 (11.20\%) & 0.186 \\
\hline Pneumonia & 57 (15.50\%) & 43 (17.8\%) & 0.443 \\
\hline Length of stay & $13.23 \pm 18.158$ & $14.25 \pm 9.447$ & 0.422 \\
\hline
\end{tabular}

BMI, body mass index; EGJ, esophagogastric junction; LG, thoracic duct ligation group; NLG, non-ligation group; MIS, minimally invasive surgery; ESD, endoscopic submucosal dissection.

$\mathrm{P}$ value of less than 0.05 was considered to be statistically significant.

\section{Results}

\section{Patient characteristics}

Tables 1 and 2 show the baseline data of all the patients. Before matching, a total of 241 (39.57\%) and 368 (60.43\%) patients were assigned to the LG and NLG, respectively. 
Table 2 Data of 370 patients after propensity score-matching

\begin{tabular}{|c|c|c|c|}
\hline \multirow{2}{*}{ Characteristics } & \multicolumn{3}{|c|}{ After matching } \\
\hline & NLG $(n=185)$ & LG $(n=185)$ & $P$ value \\
\hline Age (years) & $61.10 \pm 7.89$ & $61.37 \pm 7.34$ & 0.728 \\
\hline BMI $\left(\mathrm{kg} / \mathrm{m}^{2}\right)$ & $22.83 \pm 3.17$ & $22.91 \pm 2.73$ & 0.794 \\
\hline Gender & & & 0.321 \\
\hline Male & $139(75.10)$ & $147(79.50)$ & \\
\hline Female & $46(24.90)$ & $38(20.50)$ & \\
\hline Hypertension & $47(25.40)$ & $45(24.30)$ & 0.810 \\
\hline Diabetes & $12(6.50)$ & $9(4.90)$ & 0.500 \\
\hline Smoking history & $105(56.80)$ & $109(58.90)$ & 0.674 \\
\hline Drinking history & $77(41.60)$ & $78(42.20)$ & 0.916 \\
\hline Tumor location & & & 0.597 \\
\hline Upper third thoracic & $11(5.90)$ & $13(7.00)$ & \\
\hline Middle third thoracic & $125(67.60)$ & $113(61.10)$ & \\
\hline Lower third thoracic & $48(25.90)$ & $57(30.80)$ & \\
\hline EGJ & $1(0.50)$ & $2(1.10)$ & \\
\hline Surgical approaches & & & 0.591 \\
\hline Sweet & $97(52.40)$ & $104(56.20)$ & \\
\hline Ivor-Lewis & $29(15.70)$ & $31(16.80)$ & \\
\hline McKeown & 59 (31.90) & $50(27.00)$ & \\
\hline Pathological T classification & & & 0.846 \\
\hline Tis & $6(3.20)$ & $3(1.60)$ & \\
\hline $\mathrm{T} 1$ & $43(23.20)$ & $43(23.20)$ & \\
\hline T2 & $50(27.00)$ & $49(26.50)$ & \\
\hline T3 & $81(43.80)$ & 83 (44.90) & \\
\hline $\mathrm{T} 4$ & $5(2.70)$ & $7(3.80)$ & \\
\hline
\end{tabular}

Table 2 (continued)

The patients in the LG were significantly younger than those of NLG (60.98 \pm 7.362 vs. $62.36 \pm 8.246 ; \mathrm{P}=0.036)$. NLG had more patients with EGJ tumors $(30.10 \%$ vs. $0.80 \% ; \mathrm{P}<0.001)$ and adenocarcinomas $(28.80 \%$ vs. $2.10 \%$; $\mathrm{P}<0.001)$, while the LG included more patients with $\mathrm{pN} 0$ stage $(58.90 \%$ vs. $45.90 \% ; \mathrm{P}<0.001)$ and neoadjuvant therapy (2.9\% vs. $0.5 \%$; $\mathrm{P}=0.044)$. A total of $260(70.70 \%)$ patients in the NLG received the Sweet procedure,
Table 2 (continued)

\begin{tabular}{|c|c|c|c|}
\hline \multirow{2}{*}{ Characteristics } & \multicolumn{3}{|c|}{ After matching } \\
\hline & NLG (n=185) & LG (n=185) & $P$ value \\
\hline Pathological N classification & & & 0.436 \\
\hline NO & $98(53.00)$ & $100(54.10)$ & \\
\hline N1 & $57(30.80)$ & $61(33.00)$ & \\
\hline N2 & $20(10.80)$ & $20(10.80)$ & \\
\hline N3 & $10(5.40)$ & $4(2.20)$ & \\
\hline Pathological types & & & 0.983 \\
\hline Adenocarcinoma (AD) & $4(2.20)$ & $4(2.20)$ & \\
\hline Squamous cell (SC) & $165(89.20)$ & $166(89.70)$ & \\
\hline Others & $16(8.60)$ & $15(8.10)$ & \\
\hline Differentiation & & & 0.975 \\
\hline G1 & $20(10.80)$ & $22(11.90)$ & \\
\hline G2 & $127(68.60)$ & $127(68.60)$ & \\
\hline G3 & $20(10.80)$ & $20(10.80)$ & \\
\hline NA & $18(9.70)$ & $16(8.60)$ & \\
\hline MIS & $45(24.30)$ & $39(21.10)$ & 0.457 \\
\hline Neoadjuvant & $1(0.50 \%)$ & $2(1.10 \%)$ & 1.000 \\
\hline ESD & $4(2.20 \%)$ & $5(2.70 \%)$ & 1.000 \\
\hline Chylothorax & $3(1.60 \%)$ & $2(1.10 \%)$ & 1.000 \\
\hline Anastomotic leak & $18(9.70 \%)$ & $18(9.70 \%)$ & 1.000 \\
\hline Recurrent nerve palsy & $1(0.50 \%)$ & $5(2.70 \%)$ & 0.217 \\
\hline Arrhythmia & 33 (17.80\%) & 22 (11.90\%) & 0.108 \\
\hline Pneumonia & 41 (22.20\%) & 35 (18.90\%) & 0.440 \\
\hline Length of stay & $14.99 \pm 25.037$ & $14.28 \pm 9.403$ & 0.719 \\
\hline
\end{tabular}

BMI, body mass index; EGJ, esophagogastric junction; LG, thoracic duct ligation group; NLG, non-ligation group; MIS, minimally invasive surgery; ESD, endoscopic submucosal dissection.

compared with $54.80 \%$ of patients in the LG $(\mathrm{P}<0.001)$. Furthermore, tumor differentiation in the LG was better than that in the NLG (G1:12.90\% vs. $6.30 \% ; \mathrm{P}=0.014)$. There were no significant differences in $\mathrm{BMI}$, gender, comorbidities, pT stage, smoking and drinking history, MIS, or ESD between the two groups. After PSM, the cohorts were narrowed to 185 patients in each group. All of the baseline data were comparable between the two groups. 

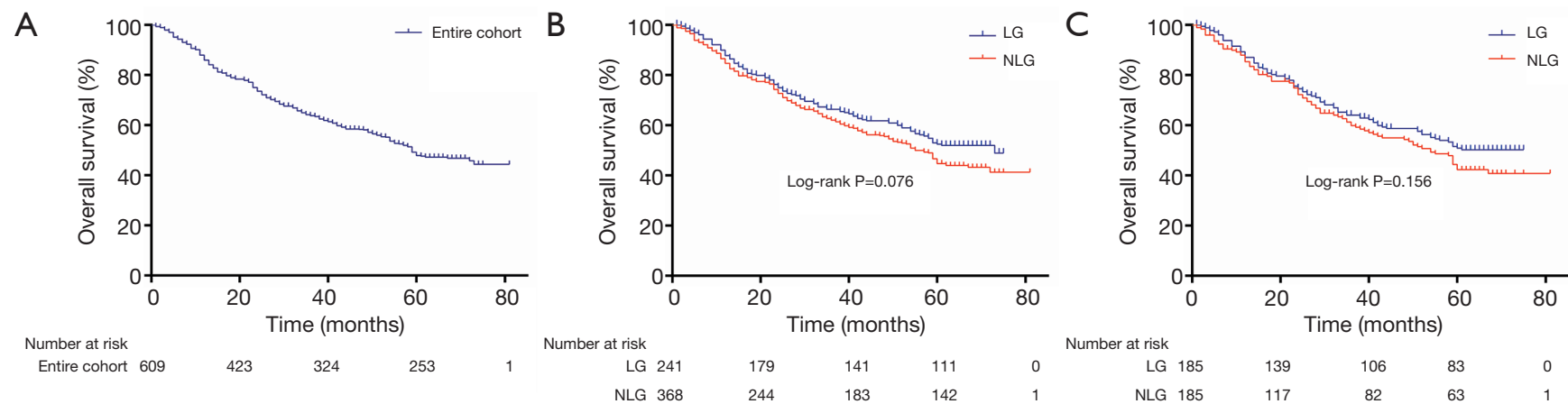

Figure 1 Kaplan-Meier plots depicting the overall survival (OS) rates of the study population. (A) Comparison of OS between the LG and NLG, (B) before and (C) after propensity score matching. Graphs displaying the number of patients at risk at different time points.

\section{Postoperative complications}

Postoperative chylothorax occurred in 2 patients in the LG $(0.83 \%)$ and 3 patients in the NLG $(0.81 \%)$, with no significant difference $(\mathrm{P}=1.000)$. Except for reoperation in 1 patient in the LG, the 4 other patients were treated with conservative approaches, and there were no hospital mortalities among these patients. No significant difference was found between the two groups for incidence of anastomotic leak, recurrent nerve palsy, arrhythmia, or pneumonia, nor was a significant difference found in length of hospital stay, as shown in Table 1. After PSM, chylothorax incidence in the LG was lower than that of the NLG $(1.1 \%$ vs. $1.6 \%)$, although this difference was not significant $(\mathrm{P}=1.000)$. LTD did not increase the risk of anastomotic leak $(9.7 \%$ vs. $9.7 \% ; \mathrm{P}=1.000)$, recurrent nerve palsy (2.7\% vs. $0.5 \% ; \mathrm{P}=0.217)$, arrhythmia $(11.90 \%$ vs. $17.80 \%$; $\mathrm{P}=0.108)$, pneumonia (18.9\% vs. $22.2 \% ; \mathrm{P}=0.440)$, or length of hospital stay $(14.28 \pm 9.403$ vs. $14.99 \pm 25.037 ; \mathrm{P}=0.719)$.

\section{Long-term survival}

The median survival time for the entire cohort was 59 months (95\% CI: 51.159-66.841 months), and the 1-, 3-5-year survival rates were $85.9 \%, 63.8 \%, 47.9 \%$, respectively (Figure 1A). The cumulative survival rates of the patients in the LG did not differ significantly from the survival rates of the patients in the NLG $(\mathrm{P}=0.076)$, with 5 -year survival rates of $52.4 \%$ and $44.7 \%$, respectively (Figure 1B). After PSM, the 1-, 3-, and 5-year survival rates were $87.0 \%, 64.1 \%$, and $50.9 \%$ in the LG, respectively, compared to $85.4 \%, 59.9 \%$, and $42.3 \%$ respectively in the NLG (Figure 1C), and this difference was not statistically significant $(\mathrm{P}=0.156)$.

\section{Univariate and multivariate analyses of prognostic factors}

Before matching, univariate Cox regression analyses showed that pathological $\mathrm{T}$ stage and pathological $\mathrm{N}$ stages were significantly associated with OS. Hence, $\mathrm{pT}$ and $\mathrm{pN}$ stages, as well as ligation, were included in the multivariate analysis. The list of independent risk factors was narrowed to $\mathrm{pT}$ stage $(\mathrm{P}=0.024)$ and $\mathrm{pN}$ stage $(\mathrm{P}<0.001)$. LTD was not a significant prognostic factor in the univariate and multivariate analyses (Table 3). After PSM, BMI, tumor location, $\mathrm{pT}$ stage, and $\mathrm{pN}$ stage were correlated to OS in the univariate analyses (Table 4). In the multivariate analyses, ligation was still not significantly associated with OS (OR, 1.251; 95\% CI: 0.925-1.692, $\mathrm{P}=0.147$ ).

\section{Discussion}

In this study, we compared the postoperative complications and long-term survival rates between the thoracic duct ligation group and the non-ligation group. Distinct from the study by Hou et al., this study showed that LTD had no significant impact on postoperative complications or longterm survival in patients with esophageal cancer.

Postoperative chylothorax after esophagectomy is a tremendous burden for patients. Approximately 70\% of patients require a second surgical treatment (1), and chylothorax-induced mortality rates can reach as high as $20 \%$ $(9,10)$. Since 1948, LTD has been confirmed as an effective approach to treating postoperative chylothorax. To further reduce the occurrence of chylothorax, some surgeons have proposed prophylactic ligation of the thoracic duct (PLTD), where direct or en masse LTD (11) should performed as the routine procedure without considering whether or not the TD is damaged. A recent meta-analysis including 7 clinical 
Table 3 COX regression analysis before propensity score-matching

\begin{tabular}{|c|c|c|c|c|c|c|}
\hline Characteristics & \multicolumn{3}{|c|}{ Univariate COX analysis } & \multicolumn{3}{|c|}{ Multivariate COX analysis } \\
\hline Age (years) & 1.011 & $(0.996-1.027)$ & 0.152 & & & \\
\hline $\mathrm{BMI}\left(\mathrm{kg} / \mathrm{m}^{2}\right)$ & 0.964 & $(0.926-1.003)$ & 0.070 & & & \\
\hline Gender (man vs. female) & 1.052 & $(0.796-1.392)$ & 0.721 & & & \\
\hline Diabetes (yes vs. no) & 1.034 & $(0.624-1.712)$ & 0.898 & & & \\
\hline Smoking history (yes vs. no) & 1.018 & $(0.806-1.285)$ & 0.883 & & & \\
\hline Drinking history (yes vs. no) & 1.005 & $(0.792-1.274)$ & 0.968 & & & \\
\hline Tumor location & & & 0.430 & & & \\
\hline Middle third thoracic & 1.145 & $(0.827-1.584)$ & 0.415 & & & \\
\hline Lower third thoracic & 1.017 & $(0.712-1.452)$ & 0.928 & & & \\
\hline Surgical approaches & & & 0.758 & & & \\
\hline Sweet & 1 & - & - & & & \\
\hline Ivor-Lewis & 1.123 & $(0.803-1.571)$ & 0.498 & & & \\
\hline Mckeown & 1.068 & $(0.800-1.427)$ & 0.655 & & & \\
\hline Ligation (yes vs. no) & 0.807 & $(0.636-1.025)$ & 0.079 & 0.917 & $(0.716-1.176)$ & 0.495 \\
\hline Pathological T classification & & & $<0.001$ & & & 0.024 \\
\hline Pathological $\mathrm{N}$ classification & & & $<0.001$ & & & $<0.001$ \\
\hline No & 1 & - & - & 1 & - & - \\
\hline N1 & 1.910 & $(1.464-2.493)$ & $<0.001$ & 1.676 & $(1.274-2.204)$ & $<0.001$ \\
\hline $\mathrm{N} 2$ & 2.791 & (1.996-3.903) & $<0.001$ & 2.291 & $(1.613-3.255)$ & $<0.001$ \\
\hline N3 & 2.513 & $(1.544-4.089)$ & $<0.001$ & 1.974 & $(1.188-3.278)$ & 0.009 \\
\hline Pathological types & & & 0.347 & & & \\
\hline Adenocarcinoma (AD) & 1 & - & - & & & \\
\hline Squamous cell (SC) & 1.228 & $(0.894-1.688)$ & 0.205 & & & \\
\hline Others & 1.008 & $(0.602-1.690)$ & 0.975 & & & \\
\hline Differentiation & & & 0.075 & & & \\
\hline G1 & 1 & - & - & & & \\
\hline
\end{tabular}

Table 3 (continued) 
Table 3 (continued)

\begin{tabular}{lccccc}
\hline \multirow{2}{*}{ Characteristics } & \multicolumn{3}{c}{ Univariate COX analysis } & & \multicolumn{2}{c}{ Multivariate COX analysis } \\
\cline { 2 - 5 } \cline { 4 - 5 } G2 & $\mathrm{HR}$ & $95 \% \mathrm{Cl}$ & $\mathrm{P}$ value & $\mathrm{HR}$ & 0.182 \\
G3 & 1.378 & $(0.860-2.207)$ & $\mathrm{Pl}$ value \\
NA & 1.777 & $(1.049-3.010)$ & 0.032 \\
MIS (yes vs. no) & 1.047 & $(0.566-1.934)$ & 0.884 \\
Neoadjuvant (yes vs. no) & 1.059 & $(0.778-1.440)$ & 0.716 \\
ESD (yes vs. no) & 1.520 & $(0.627-3.683)$ & 0.354 \\
\hline
\end{tabular}

BMI, body mass index; EGJ, esophagogastric junction; MIS, minimally invasive surgery; ESD, endoscopic submucosal dissection.

Table 4 COX regression analysis after propensity score-matching

\begin{tabular}{|c|c|c|c|c|c|c|}
\hline Characteristics & \multicolumn{3}{|c|}{ Univariate COX analysis } & \multicolumn{3}{|c|}{ Multivariate COX analysis } \\
\hline Age (years) & 1.016 & $(0.995-1.037)$ & 0.133 & & & \\
\hline BMI $\left(\mathrm{kg} / \mathrm{m}^{2}\right)$ & 0.942 & (0.895-0.992) & 0.025 & 0.950 & $(0.904-0.998)$ & 0.042 \\
\hline Gender (man vs. female) & 1.094 & $(0.773-1.549)$ & 0.611 & & & \\
\hline Diabetes (yes vs. no) & 1.170 & $(0.635-2.155)$ & 0.615 & & & \\
\hline Smoking history (yes vs. no) & 1.126 & $(0.834-1.521)$ & 0.440 & & & \\
\hline Drinking history (yes vs. no) & 1.053 & $(0.778-1.426)$ & 0.738 & & & \\
\hline Tumor location & & & 0.022 & & & 0.005 \\
\hline Middle third thoracic & 1.110 & $(0.155-7.949)$ & 0.917 & 2.018 & $(0.271-15.026)$ & 0.493 \\
\hline Lower third thoracic & 0.698 & $(0.095-5.098)$ & 0.723 & 1.131 & $(0.150-8.530)$ & 0.905 \\
\hline Surgical approaches & & & 0.999 & & & \\
\hline Sweet & 1 & - & - & & & \\
\hline Ivor-Lewis & 1.009 & $(0.662-1.537)$ & 0.967 & & & \\
\hline McKeown & 1.002 & $(0.712-1.410)$ & 0.993 & & & \\
\hline Ligation (yes vs. no) & 0.808 & $(0.600-1.088)$ & 0.160 & 1.251 & $(0.925-1.692)$ & 0.147 \\
\hline Pathological T classification & & & 0.001 & & & 0.001 \\
\hline
\end{tabular}

Table 4 (continued) 
Table 4 (continued)

\begin{tabular}{|c|c|c|c|c|c|c|}
\hline Characteristics & \multicolumn{3}{|c|}{ Univariate COX analysis } & \multicolumn{3}{|c|}{ Multivariate COX analysis } \\
\hline Pathological N classification & & & $<0.001$ & & & $<0.001$ \\
\hline NO & 1 & - & - & 1 & - & - \\
\hline N1 & 1.963 & $(1.409-2.736)$ & $<0.001$ & 1.604 & $(1.132-2.272)$ & 0.008 \\
\hline N3 & 3.215 & $(1.468-7.044)$ & 0.004 & 3.259 & $(1.449-7.330)$ & 0.004 \\
\hline Pathological types & & & 0.494 & & & \\
\hline Adenocarcinoma (AD) & 1 & - & - & & & \\
\hline Squamous cell (SC) & 1.519 & $(0.376-6.127)$ & 0.557 & & & \\
\hline G1 & 1 & - & - & & & \\
\hline G2 & 1.497 & $(0.876-2.560)$ & 0.140 & & & \\
\hline G3 & 2.010 & $(1.048-3.855)$ & 0.036 & & & \\
\hline NA & 1.215 & $(0.586-2.517)$ & 0.600 & & & \\
\hline MIS (yes vs. no) & 0.959 & $(0.667-1.379)$ & 0.821 & & & \\
\hline Neoadjuvant (yes vs. no) & 0.569 & $(0.080-4.063)$ & 0.574 & & & \\
\hline ESD (yes vs. no) & 0.047 & $(0.001-2.025)$ & 0.111 & & & \\
\hline
\end{tabular}

BMI, body mass index; EGJ, esophagogastric junction; MIS, minimally invasive surgery; ESD, endoscopic submucosal dissection.

studies and 5,254 patients confirmed the utility of PLTD in reducing chylothorax (12). In our study, we performed LTD when intraoperative chylous leakage occurred, or injury to the thoracic duct was highly suspected. Result showed that there was no significant difference in chylothorax incidence between the two groups ( $1.1 \%$ vs. $1.6 \%$; $\mathrm{P}=1.000)$. All 3 patients with postoperative chylothorax in the NLG underwent conservative treatment, with a success rate of $100 \%(3 / 3)$, whereas the success rate of conservative treatment in the LG was $50 \%(1 / 2)$. Those may be attributed to the low incidence of postoperative chylothorax (5/609; $0.82 \%$ ) and small number of enrolled patients. Except for chylothorax, no significant differences between the groups were found for the incidence of complications, which is consistent with a study by Guo et al. (13). Overall, LTD did not increase postoperative complications.

Most of the existing studies emphasize the prevention of postoperative chylothorax, while neglecting other potential consequences of LTD (7). The impact of LTD on long-term survival has yet to be comprehensively understood. Hou et al. compared the survival rates of patients in the LG and NLG, and found that LTD could reduce the OS of patients with esophageal cancer (8). Mechanistically, they attributed the decreased OS in the LG to the loss of immune factors, lipids, and proteins caused by LTD, which warrants further investigation. Growing evidence contradicts these findings. Ehrenhaft et al. (14) reported that blood fat levels dropped significantly after LTD; however, they gradually rose again to baseline levels within 2 weeks. In a study by Liu et al. (15), blood LDL levels gradually recovered within 3 months after decreasing in the first month, while cholesterol, triglycerides, and HDL showed no significant differences between the two groups. In terms of lymphocyte loss, Lee et al. found that lymphocyte counts were significantly reduced after LTD but recovered to normal levels after 3 weeks (16). Taken together, these studies suggest that the metabolic and immunologic changes caused by LTD might be transient. In addition, there was significant heterogeneity between the 
variables of the LG and NLG in Hou et al.'s study, which might reduce the credibility of the results.

In our study, 1:1 propensity score matching was used to minimize the potential differences between the two groups. We observed that LTD had no obvious influence on OS neither before nor after PSM. Moreover, univariate and multivariate Cox analyses demonstrated that LTD was not a significant prognostic factor, which further validated our primary endpoint findings. Although there were no significant differences between the two groups, KaplanMeier plots demonstrated that the 5-year survival rate of the LG was greater than that of the NLG. This could be explained by the fact that the NLG had more patients with $\mathrm{pN} 3$ stage and comorbidities, while the LG had more patients with N0-1, G1, and MIS.

In clinical practice, LTD is usually well tolerated due to collateral circulations or the opening of lymphaticovenous communications (17). Although the thoracic duct usually has only one main channel, multiple channels with significant variation can be found in $40 \%$ cases (18). In a study by Davis et al. (19), the thoracic ducts of $27.27 \%$ patients began in the abdominal cavity as the two channels extended cephalad through the thorax, lying on each side of the aorta, with cross anastomosing channels connecting the two ducts. In addition, there are 3 types of lymphaticovenous communications (LVC) in humans: the central LVC (the termination of thoracic duct), peripheral LVC (communication between lymphatic vessels and veins), and the LVC within lymph nodes $(17,20-23)$. Once the thoracic duct is ligated, the latter two types play a compensatory role in lymphatic return. Peripheral LVCs exist between the lymphatic system and different veins such as the portal vein, the inferior vena cava, the azygos, and the superior vena cava (17). Due to regional obstruction of the lymphatic system, peripheral LVCs were also found in the thigh, leg, and foot $(24,25)$. Located within the paracortex of the lymph nodes are high endothelial venules (HEV), which are specialized vessels that enable direct communication between the lymph and the blood (20). Under pathological conditions, large LVCs within the medulla of lymph nodes may occur once valve incompetency or lymphatic failure takes place (17). Therefore, after LTD, peripheral LVC or lymph node LVC plays a compensatory role in lymphatic circulation.

This study has several limitations. Firstly, the singlecenter, retrospective nature of this study may have introduced selection bias. Well-designed multi-center randomized controlled trials are needed to validate our results. Secondly, PSM excluded unmatched individuals from the analysis, which reduced the sample size and affected the results. Thirdly, due to difficulty during followup, we did not analyze indicators that are reflective of nutritional status.

In conclusion, our study demonstrated that LTD does not increase postoperative complications, and there is no significant correlation between LTD and the prognosis of patients who undergo esophagectomy.

\section{Acknowledgments}

Funding: This work was supported by the National Natural Science Foundation of China (grant number 81472688).

\section{Footnote}

Reporting Checklist: The authors have completed the STROBE reporting checklist. Available at http://dx.doi. org/10.21037/jtd-20-1341

Data Sharing Statement: Available at http://dx.doi. org/10.21037/jtd-20-1341

Peer Review File: Available at Available at http://dx.doi. org/10.21037/jtd-20-1341

Conflicts of Interest: All authors have completed the ICMJE uniform disclosure form (available at http://dx.doi. org/10.21037/jtd-20-1341). The authors have no conflicts of interest to declare.

Ethical Statement: The authors are accountable for all aspects of the work in ensuring that questions related to the accuracy or integrity of any part of the work are appropriately investigated and resolved. The study was conducted in accordance with the Declaration of Helsinki (as revised in 2013). The study was approved by Ethics Committee of Changhai Hospital (CHEC-2019-359) and informed consent was taken from all the patients.

Open Access Statement: This is an Open Access article distributed in accordance with the Creative Commons Attribution-NonCommercial-NoDerivs 4.0 International License (CC BY-NC-ND 4.0), which permits the noncommercial replication and distribution of the article with the strict proviso that no changes or edits are made and the original work is properly cited (including links to both the 
formal publication through the relevant DOI and the license). See: https://creativecommons.org/licenses/by-nc-nd/4.0/.

\section{References}

1. Chen KN. Managing complications I: leaks, strictures, emptying, reflux, chylothorax. J Thorac Dis 2014:S355-63.

2. Miao $\mathrm{L}$, Zhang $\mathrm{Y}, \mathrm{Hu} \mathrm{H}$, et al. Incidence and management of chylothorax after esophagectomy. Thorac Cancer 2015;6:354-8.

3. Bryant AS, Minnich DJ, Wei B, et al. The incidence and management of postoperative chylothorax after pulmonary resection and thoracic mediastinal lymph node dissection. Ann Thorac Surg 2014;98:232-5; discussion 235-7.

4. Kranzfelder M, Gertler R, Hapfelmeier A, et al. Chylothorax after esophagectomy for cancer: impact of the surgical approach and neoadjuvant treatment: systematic review and institutional analysis. Surg Endosc 2013;27:3530-8.

5. Sauvanet A. Surgery technique: preventive ligation of the thoracic duct during esophagectomy for cancer. Ann Chir 2002;127:228-31.

6. Lampson RS. Traumatic chylothorax; a review of the literature and report of a case treated by mediastinal ligation of the thoracic duct. J Thorac Surg 1948;17:778-91.

7. Choh CT, Khan OA, Rychlik IJ, et al. Does ligation of the thoracic duct during oesophagectomy reduce the incidence of post-operative chylothorax? Int J Surg 2012;10:203-5.

8. Hou X, Fu JH, Wang X, et al. Prophylactic thoracic duct ligation has unfavorable impact on overall survival in patients with resectable oesophageal cancer. Eur J Surg Oncol 2014;40:1756-62.

9. Mishra PK, Saluja SS, Ramaswamy D, et al. Thoracic duct injury following esophagectomy in carcinoma of the esophagus: ligation by the abdominal approach. World J Surg 2013;37:141-6.

10. Shah RD, Luketich JD, Schuchert MJ, et al. Postesophagectomy chylothorax: incidence, risk factors, and outcomes. Ann Thorac Surg 2012;93:897-903; discussion 903-4.

11. Lin Y, Li Z, Li G, et al. Selective En Masse Ligation of the Thoracic Duct to Prevent Chyle Leak After Esophagectomy. Ann Thorac Surg 2017;103:1802-7.

12. Crucitti P, Mangiameli G, Petitti T, et al. Does prophylactic ligation of the thoracic duct reduce chylothorax rates in patients undergoing oesophagectomy? A systematic review and meta-analysis. Eur J Cardiothorac Surg 2016;50:1019-24.

13. Guo W, Zhao YP, Jiang YG, et al. Prevention of postoperative chylothorax with thoracic duct ligation during video-assisted thoracoscopic esophagectomy for cancer. Surg Endosc 2012;26:1332-6.

14. Ehrenhaft JL, Meyers R. Blood fat levels following supradiaphragmatic ligation of the thoracic duct. Ann Surg 1948;128:38-45.

15. Liu JP, Zhang YH, Yang B, et al. Influence of thoracic duct ligation on the lipid metabolism of patients with esophageal carcinoma after esophagectomy. Genet Mol Res 2015;14:2527-36.

16. Lee FC. Changes in the number of small lymphocyte of the blood following ligation of the thoracic duct. J Exp Med 1922;36:247-60.

17. Hidden G, Menard P, Zorn JY. Lymphaticovenous communications. Role of the lymph nodes. Anat Clin 1985;7:83-91.

18. Phang K, Bowman M, Phillips A, et al. Review of thoracic duct anatomical variations and clinical implications. Clin Anat 2014;27:637-44.

19. Davis HK. A Statistical Study of the Thoracic Duct in Man. Am J Anat 1915;17:211-44.

20. Miranda Garcés M, Mirapeix R, Pons G, et al. A comprehensive review of the natural lymphaticovenous communications and their role in lymphedema surgery. J Surg Oncol 2016;113:374-80.

21. Heymans O, Fallais C, Hustinx R. Intratissular lymphaticovenous anastomoses demonstrated by perioperative intramuscular injection of 99mTC-colloids. Lymphat Res Biol 2006;4:29-33.

22. Stamp GF, Peters AM. Peripheral lymphovenous communication in lymphoedema. Nucl Med Commun 2012;33:701-7.

23. Koehler PR, Schaffer B. Peripheral lymphaticovenous anastomoses. Report of two cases. Circulation 1967;35:401-4.

24. Kariya S, Komemushi A, Nakatani M. Intranodal lymphangiogram: technical aspects and findings. Cardiovasc Intervent Radiol 2014;37:1606-10.

25. Threefoot SA, Kossover MF, Kent WT, et al. Factors stimulating function of lymphaticovenous communications. Angiology 1967;18:682-98.

Cite this article as: Fei X, Wang X, Lu Q, Lu C, Chen H, Li C. The influence of thoracic duct ligation on long-term survival of patients with esophageal cancer: a propensity score-matched analysis. J Thorac Dis 2020;12(10):5532-5541. doi: 10.21037/jtd20-1341 